\title{
Monitoramento e Controle para um sistema solar de Aquecimento de água industrial
}

J. Bione, M. F.

Escola Politécnica de Pernambuco

Universidade de Pernambuco

50.720-001 - Recife, Brasil

jbionef@bol.com.br

jbionef@poli.br
Ramos, M. P.

Escola Politécnica de Pernambuco

Universidade de Pernambuco

50.720-001 - Recife, Brasil

monalyzapr@mail.com

Resumo Este trabalho apresenta o grande potencial de geração de energia solar no Brasil e principalmente no Nordeste. Descrevemos os principais sistemas de aquecimento de água por energia solar, além de Estudar o funcionamento e implementar melhorias no sistema de aquecimento do óleo do motor-gerador contido na planta de geração de energia da Termocabo S.A.

Abstract This work shows the great potential for solar power generation in Brazil and especially in the Northeast. It describe the main systems of water heating by solar energy and study his operation. we also implement improvements in the heating oil motor generator contained in the plant's power generation Termocabo SA. 


\section{Introdução}

A principal fonte de energia da terra é o sol, responsável por $99 \%$ do seu balanço energético, portanto uma eximia fonte de energia renovável. Diversos estudos e pesquisas comprovam a eficiência e a viabilidade econômica da tecnologia termossolar.

A empresa TERMOCABO Ltda, usina termoelétrica de carga nominal de $48 \mathrm{MW}$ situada na cidade do Cabo de Santo Agostinho, constituída por três motores Wärtsilä $18 \mathrm{~V} 46$, os quais utilizam como combustível o óleo pesado (HFO), necessita manter o óleo destes motores pré-aquecidos, através de troca de calor com um fluido quente, no caso a agua. Atualmente o aquecimento do óleo é realizado por uma caldeira, que utiliza como combustível o gás natural.

Devido aos impactos ambientais e ao alto custo referente ao gás natural, a Termocabo decidiu iniciar um projeto de Pesquisa e desenvolvimento (P\&D) com A Associação Politécnica de Consultoria - POLICONSULT, sociedade civil sem fins lucrativos, formada por professores da Escola Politécnica da Universidade de Pernambuco (POLI-UPE), almejando à implementação de coletores solares planos para substituir a caldeira.

Este projeto já se encontra em andamento na POLI-UPE, e esta pesquisa refere-se ao uso de uma bomba hidráulica acionada por uma placa solar, que deve ser adicionado ao projeto, de forma a melhoras seu desempenho e garante uma maior versatilidade quanto ao posicionamento dos componentes da instalação.

\section{Introdução}

A transmissão de energia solar para a Terra se dá através da radiação eletromagnética, porém ao atingir o limite superior da atmosfera terrestre, a radiação sofre uma série de reflexões, absorções e dispersões durante seu percurso até o solo e esses processos estão sujeitos a influências, sendo elas condições do céu, estações do ano, latitude, condições atmosféricas e hora do dia.

Dois conceitos importantes utilizados no estudo da energia solar são os conceitos da irradiância e irradiação. A irradiância é vista como sendo a densidade de potência incidente em sua superfície por unidade de tempo, no caso da irradiação pode ser conceituada como uma energia incidente por unidade de tempo.

Em termos de unidade temos que a irradiância é medida em $\mathrm{kW} / \mathrm{m}^{2}$, a irradiação por sua vez tem como unidade de medida $\mathrm{kWh} / \mathrm{m}^{2}$ ou qualquer unidade equivalente.

\section{Sistema de Aquecimento de Agua por Energia Solar}

Os principais componentes que compõem um sistema de aquecimento de agua por energia solar são: o coletor e os reservatórios térmicos.

O coletor é o componente mais importante de um sistema de aquecimento solar, pois é ele o responsável pela conversão da energia solar em energia térmica. É comporto por uma cobertura transparente ou translucida, uma superfície absorvedora e um sistema de transferência de calor.

O absorvedor é a parte do coletor responsável pela recepção, absorção, conversão e transferência da energia solar captada para o fluido de trabalho. O gabinete também faz parte do coletor e tem por finalidade isolar o absorvedor do meio ambiente.

Os reservatórios podem ser de agua quente, fria. Os de água quente também são chamados de boilers e fabricados geralmente em aço inoxidável ou cobre. Os boilers são constituídos por duas superfícies cilíndricas um interna e outra externa tendo entre as mesmas um isolante térmico.

\section{Funcionamento dos Coletores Pla- nos}

No que se refere ao funcionamento do sistema de aquecimento solar, podemos verificar que consiste na passagem do calor pelas placas planas ou aletas ocorrendo da seguinte forma. Os raios solares incidem através da cobertura de vidro, parte da radiação é refletida por esta cobertura, e parte absorvida, esquentando-a, esta se aquece e parte do calor é conduzida para a serpentina de tubos onde circula a água, que recebe este calor por convecção.

A cobertura de vidro superior diminui as perdas de calor por convecção natural com o ar, se o vidro for opaco à radiação de raios infravermelhos da superfície absorvedora causa o efeito estufa. Isto faz com que parte das perdas por radiação desta superfície negra e dos tubos, exista uma camada de material isolante térmico, sendo este conjunto fechado em uma caixa que também auxilia no isolamento.

Quanto a forma do fluido passar pelo coletor, podemos classificar o sistemas em dois grades grupos, os sistemas passivos onde o fluido passa pelo coletor por um processo chamado de termofissão, que ocorre graças a uma força motriz que decorre da diferença de densidade do fluido. Já no sistema ativo, deve ser adicionada ao projeto uma bomba hidráulica para forçar o fluido a percorrer o coletor. 


\section{Projeto TERMOCABO}

O projeto solicitado pela TERMOCABO Ltda a POLICONSULT busca implementando a utilização de coletores solares planos, que utilizam superfícies concentradoras na forma de parábolas truncadas que refletem a radiação solar no seu eixo onde um tubo absorvedor recebe esta energia. Pelo interior do tubo circula um fluido, no caso desse projeto é a água, a ser aquecido, em substituição ao sistema de gás natural que também realiza o pré-aquecimento da água que troca calor com o óleo utilizado nos blocos dos motores da Usina Termocabo.

\section{Bomba Hidráulica}

o sistema de aquecimento será um sistema ativo, e a bomba hidráulica escolhida para o projeto da termocabo é a minibomba da marca POWERFIX, está bomba foi escolhida por possuir o grande diferencial de poder ser acionada pelo motor de uma furadeira convencional, dessa forma, o nosso sistema pode ser utilizado em aplicações industriais e residenciais, já que a furadeira é um equipamento que pode que a maioria das pessoas possui em casa, além de apresentar baixo curto e fácil instalação, abaixo podemos ver como ela é utilizada e suas partes constituintes.

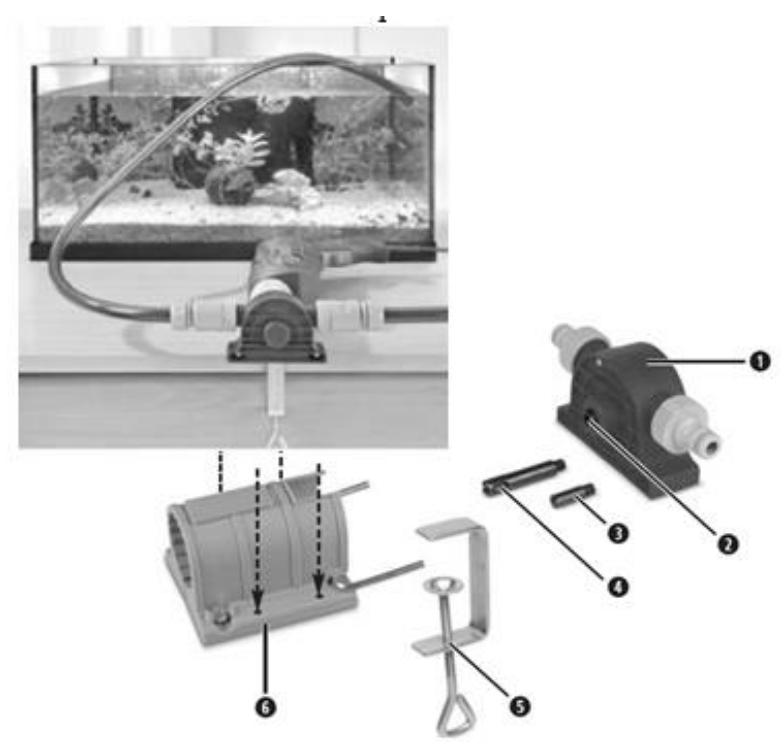

Figura 4 - Bomba hidráulica

1. Bomba

2. Eixo de acionamento da bomba

3. Haste de acionamento pequena

4. Haste de acionamento grande
5. Dispositivo de fixação por aperto Suporte.

Para o acionamento da bomba será utilizado uma placa solar e um inversor de frequência. A placa fornece $12 \mathrm{~V}$ de tensão continua, que alimenta o inversor, o inversor tem a finalidade de transformar a tensão continua em uma tensão alternada, no nosso caso $220 \mathrm{~V}$ de tensão alternada. O inversor utiliza transistores IBGTs(transistor bipolar com gate isolado), através de uma logica de controle, os transistores são "ligados e desligados" de modo a alterar a intensidade e o sentido de corrente que circula pelo motor.

\section{Células fotovoltaicas}

No sistema fotovoltaico a energia proveniente do sol é transformada diretamente em eletricidade. As células fotovoltaicas são os dispositivos responsáveis por este processo de conversão. As células fotovoltaicas são constituídas por um material semicondutor, o silício, ao qual são adicionadas substancias, ditas dopantes, de modo a crias um meio adequado ao estabelecimento do efeito fotovoltaico, isto é, conversão direta da potencia associada a radiação solar em potencia elétrica CC. ( Rui M. G. Castro, 2008).

Visando ampliar os conhecimentos a respeito da energia solar e a geração de energia elétrica à partir da energia solar, foi elaborado um ensaio com duas placas solares da POLI-UPE, o ensaio seguiu da seguinte forma:

1- Conectar a placa ao simulador de carga;

2- Encontrar o valor máximo e mínimo de tensão gerado pela fonte ao variar a carga;

3- Dividir esta escala em 10 valores iguais;

4- Montar uma tabela, iniciando do menor valor de tensão e aumentando os valores ate o valor máximo, medindo simultaneamente a tensão e a corrente.

Para as duas placas medidas, foi anotado o horário das medições, a partir das medições montamos as seguintes tabelas:

Placa A
\begin{tabular}{|l|l|l|}
\hline A & V & I \\
\hline 1 & 18,35 & 0 \\
\hline 2 & 17,82 & 0,42 \\
\hline 3 & 17,51 & 0,82 \\
\hline 4 & 17,37 & 1,2 \\
\hline 5 & 16,93 & 1,6 \\
\hline
\end{tabular}




\begin{tabular}{|l|l|l|}
\hline 6 & 16,48 & 2 \\
\hline 7 & 16 & 2,43 \\
\hline 8 & 15,47 & 2,83 \\
\hline 9 & 14,5 & 3,39 \\
\hline 10 & 1,22 & 3,85 \\
\hline 11 & 0,1 & 4 \\
\hline Horário & & $11: 05$ \\
\hline
\end{tabular}

Placa B

\begin{tabular}{|l|l|l|}
\hline B & V & I \\
\hline 1 & 16,4 & 0 \\
\hline 2 & 15,98 & 0,4 \\
\hline 3 & 15,55 & 0,8 \\
\hline 4 & 15,12 & 1,2 \\
\hline 5 & 14,69 & 1,6 \\
\hline 6 & 14,17 & 2 \\
\hline 7 & 13,53 & 2,42 \\
\hline 8 & 12,65 & 2,82 \\
\hline 9 & 8,45 & 3,28 \\
\hline 10 & 0 & 3,7 \\
\hline Horário & & $10: 50$ \\
\hline
\end{tabular}

Uma curva característica de uma célula fotovoltaica é a representação dos valores da corrente (I) de saída de um conversor fotovoltaico, em função da tensão $(\mathrm{V})$. A analise da curva I x V é de fundamental importância na caracterização de um gerador fotovoltaico, pois a partir dela é possível obter-se os principais parâmetros que determinam sua qualidade e desempenho.

A ilustração abaixo representa uma célula fotovoltaica sob diversas condições de iluminação:

a) Sem iluminação a célula tem as mesmas características elétricas de um diodo;

b) Quando a célula é iluminada, sua curva I x V é deslocada para o $4^{\circ}$ quadrante;

c) Quanto maior a intensidade da radiação, maios é o deslocamento da curva;

d) A curva é, por convenção rebatida sobre o eixo das tensões, tornando o $1^{\circ}$ quadrante o quadrante de geração.

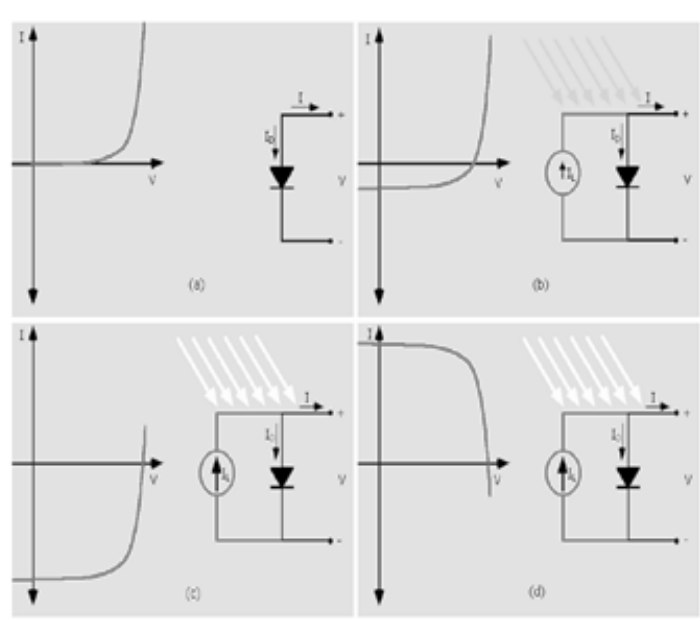

Figura 3 - Célula fotovoltaica sob diversas condições de iluminação.

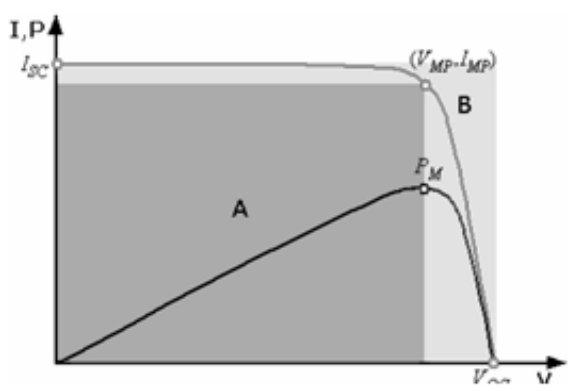

Figura 4 - Curva característica de $L x V_{2}$ e de potencia.

A curva característica apresenta três pontos notáveis, sendo eles:

1. Corrente de curto-circuito $I_{s c}$ : É a corrente que circula por uma célula iluminada quando a tensão em seus terminais é nula.

2. Tensão de circuito aberto $V_{o c}$ : É a tensão entre os terminais de uma célula iluminada quando a corrente que circula por ela é nula.

3. Ponto de máxima potencia $P_{M}$ : É o ponto da curva para o qual o produto tensão $X$ corrente é máximo. A figura abaixo mostra a curva $I x V$ (em vermelho) e a curva de potencia(em azul), destacando os pontos citados, vale salientar que o ponto $I_{s c}$ e $V_{o c}$ representam respectivamente a máxima corrente e a máxima tensão gerada pela fonte, porem estes pontos apresentam potencia de saída igual a zero, de acordo com o gráfico podemos notar que a curva da potencia ( curva azul) cresce linearmente ate atingir o ponto de máxima potencia. 
Segue abaixo as curvas geradas a partir dos dados coletados no experimento, podemos perceber que as curvas já apresentam uma certa defasagem em relação a curva ideal, isso se deve ao fato do tempo de uso das placas, mais as características principais se preservam.

Figura 5 - curva característica da placa solar A. $I_{s c}=3,7^{\mathrm{a}}$, Voc $=16,4 \mathrm{~V}$

\section{Curva Característica - B}

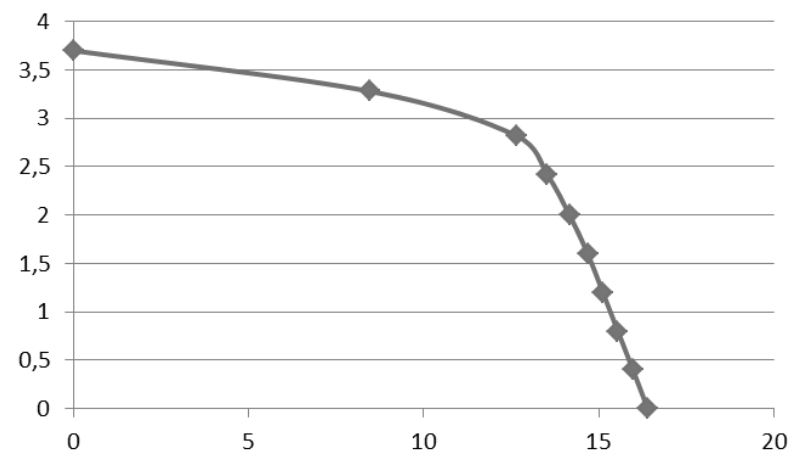

Figura 6 - curva característica da placa solar B. $I_{s c}=4^{\mathrm{a}}$, Voc $=18.35 \mathrm{~V}$

\section{Conclusão}

Diante dessa pesquisa pode-se concluir que os avanços tecnológicos já tornam o uso dos coletores viáveis e competitivos, tendo agora como maior desafio conquistar a confiança dos usuários, que esta relacionada ao custo inicial e a necessidade de fontes alternativas, vencendo-se essas barreiras á utilização de coletores planos para o aquecimento de água será a melhor opção.

O projeto implantado em conjunto com a TERMOCABO e a POLICONSULT demostra que os sistemas de aquecimento de água por energia solar já é uma opção técnica e economicamente viável, necessitando apenas de mais oportunidade no mercado.

\section{Referências}

[1] COMETTA,Emilio. Energia Solar, Utilização e Efeitos Práticos. Hermus editora.2004.

[2] LIMA, Juliana Benoni Arruda, otimização de sistema de aquecimento solar de água em edificações residenciais unifamiliares utilizando o programa TRNSYS, São Paulo,: Escola Politécnica da Universidade de São Paulo, 2003, 123p. Dissertação de mestrado.
[3] BORGES, Thomaz P. De Freitas, síntese otimizada de sistemas de aquecimento solar de água, Campinas, Universidade Estadual De Campinas, Faculdade De Engenharia Mecânica. 2000, 130p. Tese de Doutorado.

[4] MENDONÇA, Bernadette Vechia de, estudo da problemática da aplicação de coletores solares para aquecimento de água, no segmento residencial de alto padrão, com base em escalas de projeto arquitetônico e dimensões de planejamento, São Paulo, Escola Politécnica de Universidade de São Paulo, 2009, 190p. Dissertação de Mestrado.

[5] SOUZA, Karina terra de; MIRANDA, Láilly de Souza; SILVA, Márcia Almeida, Aquecimento de água através do uso de coletores planos, Bolsista de Valor: Revista de divulgação do Projeto Universidade Petrobras e IF Fluminense v. 1, p. 5157, 2010.

[6] SOUZA, Karina terra de; MIRANDA, Láilly de Souza; SILVA, Márcia Almeida, Aquecimento de água através do uso de coletores planos, Bolsista de Valor: Revista de divulgação do Projeto Universidade Petrobras e IF Fluminense v. 1, p. 5157,2010 